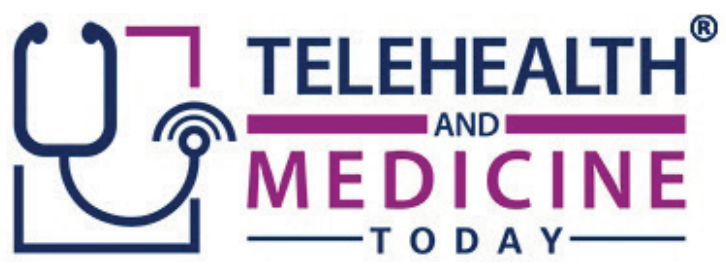

\title{
Telemedicine Provides Enhanced Care for Low-Acuity Pediatric Urology Patients
}

Nikka Khorsandi ${ }^{1,2}$, Brendon Gros ${ }^{1}$, Yu-Wen Chiu ${ }^{2}$, Aaron D. Martin ${ }^{1,2,3}$

Affiliations: ${ }^{1}$ School of Medicine, LSU Health Sciences Center New Orleans, New Orleans, LA, USA; ${ }^{2}$ School of Public Health, LSU Health Sciences Center New Orleans, New Orleans, LA, USA; ${ }^{3}$ Children's Hospital New Orleans, New Orleans, LA, USA

Corresponding author: Aaron D. Martin, Amar16@1suhsc.edu

Keywords: Patient Satisfaction, Pediatric, Quality of Care, Telehealth, Telemedicine, Urology.

Section: Original Clinical Research

Methods: A survey was developed and sent to patients participating in a pediatric teleurology program at an academic medical center. This survey evaluated the patient's history using this telemedicine platform, satisfaction with various aspects of the application as well as associated details about transportation and costs of traditional in-person visits.

Results: Of the 50 survey respondents, the majority reported that they found the app easy and comfortable to use as well as just as useful as in-person visits. Respondents also indicated that they incurred lower costs, traveled less, and faced less time lost from work.

Conclusions: Telemedicine is a useful tool to enhance low-acuity pediatric urology care while minimizing the financial and opportunity costs of these visits as compared to in-person visits.

\section{BACKGROUND}

Telemedicine allows providers to employ technology for the purposes of enhancing medical interactions with patients. While telemedicine has been employed in most medical specialties, it is especially advantageous for patients that need low-acuity evaluation by medical providers. The use of telemedicine has been shown to reduce geographic distances traveled by patients as well as the costs associated with in-person medical visits.

Telemedicine includes any form of telecommunication to diagnose and treat patients remotely and includes, but is not limited to, videoconferencing, electronic consults, and wearable devices for tele-monitoring. ${ }^{1,2}$ Owing to its wide versatility, telemedicine has grown into all fields of healthcare and is being implemented to continue improving patient care. ${ }^{3}$ 
It has been employed by many medical specialties to provide pre- and post-operative care, expand access in rural areas, and facilitate communication between consultants. ${ }^{2}$ This has worked especially well in medical specialties that face an unbalanced geographic distribution of providers such as pediatric or surgical subspecialty care. ${ }^{2,4}$ For example, these specialties have taken advantage of telementoring to improve surgeons' technical experiences or provide triage services in surrounding emergency rooms, urgent care centers, or community intensive care units. ${ }^{5}$

Some pediatric urologistswere quick to adopt the use of telemedicine and used it to address a number of low-acuity diagnoses, including urinary incontinence, vesicoureteral reflux, congenital abnormalities, dysfunctional voiding, and urinary tract infections. ${ }^{1,6}$ However, in 2016, an American Urological Association report indicated that less than $9 \%$ of all urologists participated in a telemedicine program. ${ }^{7}$ Some of the potential barriers to adoption of this type of technology by providers include cost and concerns of liability, lack of time for training, lack of technical support, lack of reimbursement, and perceived threatened clinical independence. ${ }^{8}$ With the coronavirus pandemic, many of these barriers have been pushed aside, allowing clinicians to use telemedicine to continue to care for their patients.

Owing to the centralization of pediatric urologists in urban and academic areas, patients are often required to travel long distances for medical evaluation, leading to additional costs of medical visits, including hotel stays, loss of time at work, or car rentals. ${ }^{9,10}$ Previous investigations into the use of telemedicine by pediatric urologists have indicated that telemedicine can be useful in reducing some of the associated costs of in-person visits for postoperative care. ${ }^{11,12}$
One important predictor in the success of telemedicine programs is patient satisfaction with the technology. Previous investigations into the satisfaction of care received by patients or their parents consistently demonstrated high levels of satisfaction. ${ }^{13-15}$

This study was conducted to evaluate the current satisfaction levels and sensibility of a pediatric urology telemedicine program for low-acuity clinic visits. Our telemedicine program was evaluated on its ability to reduce waiting time, distance of travel, and associated transportation costs compared to in-person visits along with markers for patient satisfaction.

\section{MATERIALS AND METHODS}

The study population surveyed was adult individuals seeking pediatric urological medical care for their dependents through the Louisiana State University Health Sciences Center (LSUHSC)/Children's Hospital of New Orleans (CHNOLA) pediatric urology program. After initial in-person evaluation with a single pediatric urologist, patients with low-acuity conditions needing follow-up that did not require a repeat physical examination (e.g., voiding dysfunction, nocturnal enuresis, routine imaging follow-up, etc.) were offered enrollment into the CHNOLA Telemedicine Enhancing Children's Health (TECH) Program. The TECH program was created in 2017 at CHNOLA with the goal of enhancing pediatric subspecialty care around the state of Louisiana. This program employed the Hale Health telemedicine platform (San Francisco, CA) to provide secure messaging, video visits, and photo-sharing between patient and provider. The survey was sent out to 117 individuals, with 50 consenting and completing the survey (response rate: $43 \%$ ) from August 2018 to December 2018 through the Hale Health telemedicine platform. Individuals who had not responded to the survey 
received a mobile notification through the Hale Health application 2 weeks after receiving the original survey.

The survey was originally developed from both a literature review focused around assessing satisfaction and utility of previous telemedicine programs, and previous satisfaction surveys employed by LSUHSC. ${ }^{16,17}$ This survey instrument contained 39 items that identified patient background, socioeconomic details, and history of telemedicine usage. It also assessed the satisfaction of utility of the mobile application, comfort with discussing clinical conditions, relationship and communication with the provider, associated costs with telemedicine visits, and details about transportation and costs of traditional, in-person visits. Questions assessing background, socioeconomic details, history of telemedicine usage, and details about in-person visits utilized multiple-choice options, while questions assessing satisfaction of utility of the platform, comfort with discussing clinical conditions, relationship and communication with the provider, and associated costs with the telemedicine visit were assessed through a 5-point Likert scale ranging from "Strongly Disagree" to "Strongly Agree" with an option for "not applicable" participants.

After the creation of the survey instrument, it was reviewed by three urologists and public health faculty at LSUHSC for face validity, content validity, and wording. The survey was sent to five patients to be reviewed in the same manner. As a result, minor editorial changes were made to optimize clarity and utility of the instrument.

Collected data were analyzed using descriptive statistics with SAS version 10.4 (SAS Institute Inc; Cary, NC). The LSUHSC institutional review board approved this study as expedited (IRB \#10165).

\section{RESULTS}

The majority of the 50 parents or caregivers of patients enrolled in CHNOLA's TECH program that responded to the survey were white and female respondents. The annual household income for patients was somewhat evenly distributed with the largest percentage of respondents falling between $\$ 20,001$ and $\$ 40,000$ a year. The education attainment level of respondents, however, fell into two groupings - a high school diploma or a college degree or higher. Insurance status was equally split between commercial and Medicaid and almost all (98\%) reported having a primary care doctor. Respondents had a history of between 1 and 15 visits with this telemedicine platform with an average of between 2 and 3 visits.

Statistics of respondents' satisfaction rates with usage of the Hale Health mobile application indicated that the vast majority found the app easy to use in terms of downloading the application, setting and rescheduling appointments, and finding a place to have the visit. In addition, responses indicate that the application allowed for patient/caregiver comfort with the medical decision process, relationship, and communication with the clinician. In evaluating satisfaction levels of the potential and associated costs, respondents indicated that slightly more than half would choose a telemedicine video visit over in-person visit because of associated costs. Seven out of 10 felt that they received the same quality of visit through video telemedicine visits and nine out of 10 reported no issues with insurance coverage of visits.

When asked about travel distances for in-person pediatric urology visits, most respondents would travel between 50 and 200 miles and would use their own car as their mode of transportation (Tables 1 and 2). Almost 20\% of respondents 
Table 1. Associated transportation costs and travel distances for in-person medical visits

\begin{tabular}{|l|c|}
\hline With in-person visits, I would travel approximately: & $\%(\boldsymbol{n})$ \\
\hline Less than 20 miles & $12 \%(6)$ \\
\hline Between 20 and 49 miles & $14 \%(7)$ \\
\hline Between 50 and 99 miles & $34 \%(17)$ \\
\hline Between 100 and 200 miles & $22 \%(11)$ \\
\hline More than 200 miles & $18 \%(9)$ \\
\hline With in-person visits, I would have incurred these travel costs: & $10 \%(5)$ \\
\hline Less than \$10 & $32 \%(16)$ \\
\hline Between $\$ 10$ and \$25 & $34 \%(17)$ \\
\hline Between $\$ 26$ and \$50 & $16 \%(8)$ \\
\hline Between $\$ 51$ and \$100 & $8 \%(4)$ \\
\hline More than \$100 & \\
\hline
\end{tabular}

Table 2. Forms of transportation and associated barriers with in-person medical visits

\begin{tabular}{|l|c|}
\hline With in-person visits, I would have used the following to travel to see the clinician: & $\%(n)$ \\
\hline Driven your own car & $98 \%(49)$ \\
\hline Taken a free ride in someone else's car & $0 \%(0)$ \\
\hline Paid for a taxi, bus, or other transport & $0 \%(0)$ \\
\hline Used transport from my health insurance company & $2 \%(1)$ \\
\hline If I traveled to see my pediatric urologist, & $58 \%(29)$ \\
\hline I would have lost time at work & $12 \%(6)$ \\
\hline My companions would have lost time from work & $32 \%(16)$ \\
\hline I would have needed to find child or adult care & $60 \%(30)$ \\
\hline I would have paid for meals while I was away from home & $10 \%(5)$ \\
\hline I would have paid for a hotel to spend the night & $36 \%(18)$ \\
\hline I would have other expenses & \\
\hline
\end{tabular}

would travel over 200 miles. Reported travel costs associated with a trip to the pediatric urologist would cost more than half of respondents between $\$ 10$ and \$50, with 8\% paying over $\$ 100$ per visit (Table 1). Some of the more common causes of these incurred travel costs include finding child or adult care and paying for food on trips, with a few paying for lodging costs. In all, $36 \%$ of respondents indicated that they would have incurred some other expense not evaluated through this survey, and $70 \%$ of respondents indicated that in-person visits to the pediatric urologist resulted in lost time at work for either themselves or a spouse/ companion (Table 2). Waiting time was shown to be reduced with the use of telemedicine visits (Table 3).

\section{DISCUSSION}

Telemedicine has previously been shown to be an acceptable modality to provide quality healthcare to patients while still maintaining patient 
Table 3. Comparing wait time for in-person and telemedicine medical visits

\begin{tabular}{|l|c|c|}
\hline Wait time & In-person visits $\%(\boldsymbol{n})$ & Telemedicine visits \% $(\boldsymbol{n})$ \\
\hline $1-14$ days & $56 \%(28)$ & $80 \%(40)$ \\
\hline $15-30$ days & $28 \%(14)$ & $14 \%(7)$ \\
\hline $31-60$ days & $14 \%(7)$ & $2 \%(1)$ \\
\hline $61-90$ days & $0 \%(0)$ & $4 \%(2)$ \\
\hline More than 90 days & $2 \%(1)$ & $0 \%(0)$ \\
\hline
\end{tabular}

satisfaction. ${ }^{18-20}$ It has become so widely employed that the American Academy of Pediatrics encourages its use to improve access to pediatric physicians while also minimizing the cost burden of providing healthcare and generating benefits to patients and their families through minimal travel costs, parents/guardians missing work, and patients missing school. ${ }^{21}$

While many publications have assessed the patient's satisfaction with telemedicine, many of these studies have limited generalizability to disparate patient populations. ${ }^{14}$ The high levels of satisfaction among the parents/guardians of pediatric urology patients in this study are consistent with similar previous evaluations. ${ }^{10,12,17}$ A reduction in out-of-pocket costs associated with in-person visits has been traditionally considered an advantage of employing telemedicine; however, willingness to pay for pediatric urology clinic visits may need further understanding to increase utility of this technology. ${ }^{22,23}$ While Louisiana has favorable coverage laws in place for telemedicine visits directly to the consumer, this is not consistent across the country or amongst payors. In evaluating some of the causes of the direct and indirect costs of in-person visits, this population reported similar sources of costs, including lost time at work, child or adult care, and meal/lodging expenses. ${ }^{10,12}$ Other costs associated with in-person visits not assessed in this study, but potentially impacting this patient population, include missed school time and loss of patient leisure time. ${ }^{22}$

In Louisiana, a largely rural state, access to pediatric urologists is concentrated in the southeast part of the state, creating a larger geographic barrier for residents in other areas of the state. In addition to the reduced travel distance that telemedicine enables for both the clinician and the patient, the reduction in number of days to be scheduled to be seen by the clinician is an added benefit, especially in a sub-specialized field such as pediatric urology. ${ }^{24}$ This is most apparent in low-acuity conditions where patients can safely wait until the clinician holds clinic at a more convenient outpatient facility where wait period is longer.

Limitations to this study include a selection bias of the population surveyed. As this survey was sent out to those who had voluntarily enrolled into the CHNOLA TECH program, it is possible that only those parents/caregivers who felt comfortable with telemedicine completed this survey and therefore the satisfaction results may be overestimated. In addition, due to the highly specialized nature of pediatric urology and a single participating clinician, a smaller number of patients and families were eligible to be surveyed, leading to the low sample size of this study. Even with these limitations, this preliminary study supports the continued and expanded use of telemedicine in pediatric 
subspecialty care while identifying potential areas of continued investigation, including, but not limited to, a comparison with patients that did not enroll in the TECH program.

\section{CONCLUSION}

Owing to the limited number of providers and specialized nature of pediatric urology, access to these clinicians can prove to be difficult due to cost or geographic barriers. Telemedicine is a widely accepted and employed method of improving access for these patients while offering a variety of cost-savings and social benefits when compared to in-person visits. In addition, patients are satisfied with the quality of care provided through the telemedicine technology. These findings encourage the current use and the future expansion of telemedicine for enhancement of low-acuity pediatric urology care.

Conflict of Interest: The authors report no conflicts of interest.

Funding Statement: The authors received no financial support for the research, authorship, and/or publication of this article.

\section{Author Contributions: All authors}

participated in the background research and survey design of this experiment, including periodic edits. A.D.M. oversaw survey implementation and data gathering. Y.W.C, N.K., and B.G. conducted data analysis. All authors participated in data interpretation. N.K. and B.G. wrote the manuscript in consultation with A.D.M. and Y.W.C. All authors approved the final version of the manuscript.

\section{REFERENCES}

1. Miller A, Rhee E, Gettman M, Spitz A. The current state of telemedicine in urology. Med ClinNorth Am. 2018;102(2):387-98.
2. Huang EY, Knight S, Guetter CR, et al. Telemedicine and telementoring in the surgical specialties: A narrative review. Am J Surg. 2019 Oct 1;218(4):760-6.

3. Kuo RL, Delvecchio FC, Babayan RK, Preminger GM. Telemedicine: Recent developments and future applications. $J$ Endourol. 2001;15(1):63-6.

4. Ray KN, Ashcraft LE, Mehrotra A, Miller E, Kahn JM. Family perspectives on telemedicine for pediatric subspecialty care. Telemed e-Health. 2017 Oct 1;23(10):852-62.

5. Harting MT, Wheeler A, Ponsky T, et al. Telemedicine in pediatric surgery. J Pediatr Surg. 2019;54:587-94. (W.B. Saunders)

6. Shivji S, Metcalfe P, Khan A, Bratu I. Pediatric surgery telehealth: Patient and clinician satisfaction. Pediatr Surg Int. 2011 May;27(5):523-6.

7. American Urological Association, The State of Urology Workforce and Practice in the United States 2015. Linthicum, Maryland, U.S.A, [cited 2016 Apr 6]. Available from: https://www.AUAnet.org/common/pdf/ research/census/State-Urology-WorkforcePractice-US.pdf

8. de Grood C, Raissi A, Kwon Y, Santana MJ. Adoption of e-health technology by physicians: A scoping review. J Multidiscip Healthc. 2016 Aug 1;9:335-44.

9. Mayer ML, Skinner AC. Too many, too few, too concentrated? A review of the pediatric subspecialty workforce literature. Arch Pediatr Adolesc Med. 2004;158:1158-65.

10. Bator EX, Gleason JM, Lorenzo AJ, et al. The burden of attending a pediatric surgical clinic and family preferences toward telemedicine. J Pediatr Surg. 2014 Dec 1;50(10):1776-82.

11. Finkelstein JB, Cahill D, Kurtz MP, et al. The use of telemedicine for the postoperative urological care of children: Results of a pilot program. J Urol. 2019 Jul 1;202(1):159-63.

12. Finkelstein JB, Cahill D, Young K, et al. Telemedicine for pediatric urologic postoperative care is safe, convenient and economical. J Urol. 2020 
Jul;204(1):144-8. https://doi.org/10.1097/ JU.0000000000000750. Epub 2020 Jan 17.

13. Marcin JP, Ellis J, Mawis R, Nagrampa E, Nesbitt TS, Dimand RJ. Using telemedicine to provide pediatric subspecialty care to children with special health care needs in an underserved rural community. Pediatrics. 2004 Jan;113(1 I):1-6.

14. Whitten P, Love B. Patient and provider satisfaction with the use of telemedicine: Overview and rationale for cautious enthusiasm. J Postgrad Med. 2005 Oct;51(4):294-300.

15. Garcia R, Adelakun O. A conceptual framework and pilot study for examining telemedicine satisfaction research. $J$ Med Syst. 2019; 43:51. https://doi.org/10.1007/ s10916-019-1161-4

16. Canon S, Shera A, Patel A, et al. A pilot study of telemedicine for postoperative urological care in children. $J$ Telemed Telecare. 2014 Dec 16;20(8):427-30.

17. Vallasciani S, Abdo B, Rauf Z, et al. Telehealth for the assessment of patients referred for pediatric urological care: A preliminary cost savings analysis and satisfaction survey. Telemed $J$ eHealth. 2019;25(8):756-61.

18. Kruse CS, Krowski N, Rodriguez B, Tran L, Vela J, Brooks M. Telehealth and patient satisfaction: A systematic review and narrative analysis. BMJ Open. 2017 Aug 1;7(8):e016242.

19. Mair F, Whitten P. Systematic review of studies of patient satisfaction with telemedicine. Br Med J. 2000 Jun 3;320(7248):1517-20.
20. Polinski JM, Barker T, Gagliano N, Sussman A, Brennan TA, Shrank WH. Patients' satisfaction with and preference for telehealth visits. $J$ Gen Intern Med. 2016 Mar 1;31(3):269-75.

21. Rimsza ME, Hotaling AJ, Keown ME, et al. The use of telemedicine to address access and physician workforce shortages. Pediatrics. 2015 Jul 1;136(1): 202-9.

22. Dávalos ME, French MT, Burdick AE, Simmons SC. Economic evaluation of telemedicine: Review of the literature and research guidelines for benefit-cost analysis. Telemed e-Health. 2009 Dec 1;15(10):933-48.

23. Martinez KA, Rood M, Jhangiani N, et al. Patterns of use and correlates of patient satisfaction with a large nationwide direct to consumer telemedicine service. $J$ Gen Intern Med. 2018 Oct 1;33(10):1768-73.

24. Hofstetter PJ, Kokesh J, Ferguson AS, Hood LJ. The impact of telehealth on wait time for ENT specialty care. Telemed $J E$ Health. 2010;16(5):551-6.

Copyright Ownership: This is an open access article distributed in accordance with the Creative Commons Attribution Non-Commercial (CC BY-NC 4.0) license, which permits others to distribute, adapt, enhance this work non-commercially, and license their derivative works on different terms, provided the original work is properly cited and the use is noncommercial. See: http://creativecommons. org/licenses/by-nc/4.0. 